\title{
Genotoxic exposure of workers creosoting wood
}

\author{
R P BOS, ${ }^{1}$ C T J HULSHOF, ${ }^{2}$ J L G THEUWS, ${ }^{1}$ AND P Th HENDERSON ${ }^{\prime}$ \\ From the Institute of Pharmacology, Toxicology Unit, ${ }^{1}$ University of Nijmegen, and the Occupational Health \\ Service, ${ }^{2}$ Region Nijmegen, Nijmegen, The Netherlands
}

ABSTRACT In a small wood preserving industry spot samples were taken from contaminated surfaces at several places and tested for mutagenicity. The results suggest that the application of a wipe test can give a first indication of occupational exposure to mutagenic and carcinogenic substances, particularly when exposure occurs more from skin contact than from inhalation. One of the pesticide chemicals used to preserve wood is the mutagenic creosote. It was found that mutagens appeared in the urine of rats after intraperitoneal administration of creosote. Despite these results, no increase in mutagenicity could be detected in the urine of creosote workers in relation to their work.

Creosote is well known as one of the pesticide chemicals used for wood preservation. It is a mixture of oils that are separated in the distillation of coal tar and consists principally of liquid and solid hydrocarbons. Because coal tar is known to contain many polycyclic aromatic hydrocarbons, we were interested to know if creosote was mutagenic and showed it to be so with the Salmonella/microsome assay.'

Because of its mutagenicity this substance might become a potential hazard to workers engaged in the preservative treatment of wood. Production workers in the wood preserving industry can be exposed to creosote not only by the inhalation of vapours but also through skin and eye contact. It is known that workers exposed to coal tar products have a high risk of cancer. ${ }^{2}$

In the present study the possibilities of detecting exposure to creosote were explored. At several places in the work area contaminated surfaces were examined for the presence of mutagens. In addition, since it was found that exposure of Wistar rats to creosote under experimental conditions leads to the excretion of mutagenic products in urine, an attempt was made to monitor creosote workers by measuring urinary mutagenicity.

\section{Material and methods}

\section{CHEMICALS}

The creosote type P1 that was used was manufactured by Cindu Chemicals BV (Uithoorn, The

Received 4 January 1983

Accepted 14 March 1983
Netherlands). Bacterial $\beta$-glucuronidase (type IX) was obtained from Sigma (St Louis, USA), Amberlite, type XAD-2 from Serva (Heidelberg FRG), purified agar from Difco Laboratories (Detroit, USA), and nutrient broth No 2 from Oxoid Ltd (Basingstoke, England). All other chemicals used were of the highest purity obtainable.

\section{IMPREGNATION PROCESS}

The impregnation of wood with creosote is accomplished by a pressure method (full cell process). After a charge of wood is taken into a cylinder, an initial vacuum is applied for a period of at least 15 minutes. The vessel is then filled with creosote having a temperature of at least $70^{\circ} \mathrm{C}\left(\right.$ mostly $\left.85-100^{\circ} \mathrm{C}\right)$, still maintaining the vacuum. Next, the vacuum is released and pressure with a maximum of $10 \mathrm{kgf} / \mathrm{cm}^{2}$ is applied to the system. Pressure is maintained until the required gross absorption of creosote has been achieved (maximal three hours). This value varies depending on the species being treated. At the end of the pressure cycle, the pressure is reduced to atmospheric level, the preservative returned to storage, and the treated wood often subjected to a final vacuum to remove excess creosote oil from the surface of the stock. The vacuum is released, the door of the vessel opened, and the treated wood removed.

\section{WORKERS}

We have studied the possible exposure of three workers. One operates the cylinder and the other two move the wood in and out of the cylinder. The operator especially would be briefly exposed to 
creosote vapour when the cylinder door is opened after treatment. The workers may also be exposed to residual surface creosote through skin contact, although most of the time they wear gloves.

\section{MUTAGENICITY TESTING}

The mutagenicity test was performed according to Ames et $^{3}{ }^{3}$ with Salmonella typhimurium TA98 and TA100. We used Oxoid nutrient broth instead of Difco nutrient broth. Rat liver S9 (9000 $g$ supernatant) fractions were prepared from male Wistar rats, pretreated with aroclor 1254; S9 mix contained $0.1 \mathrm{ml} \mathrm{S} 9$ per $\mathrm{ml}$. Every determination was done in triplicate. After incubating the plates for $48 \mathrm{~h}$ at $37^{\circ} \mathrm{C}$ the number of revertant colonies was counted.

\section{URINARY MUTAGENICITY \\ Rats}

Male Wistar rats weighing about $200 \mathrm{~g}$ were purchased from TNO (Rijswijk, The Netherlands). The animals were housed individually in stainless steel metabolic cages, designed for the separate collection or urine and faeces. The rats had free access to water and food (Hope Farms, Woerden, The Netherlands). Creosote, dissolved in olive oil, was injected intraperitoneally; control rats received injections of olive oil only.

Urine samples were collected for $24 \mathrm{~h}$ and stored at $-20^{\circ} \mathrm{C}$ until assayed. Before the assay individual samples were made up to $15 \mathrm{ml}$ and sterilised by filtration through $0.2 \mu \mathrm{m}$ membrane filters.

Mutagenicity of the urine samples was determined using the $S$ typhimurium strains TA98 and TA1003: $0 \cdot 1 \mathrm{ml}$ of a full grown suspension of the bacteria $( \pm 2$ $\times 10^{9} \mathrm{bact} / \mathrm{ml}$ ) was added to the topagar containing $0.3 \mathrm{ml}$ of diluted urine, and was supplied with an activating enzyme system. This activating enzyme system consisted of either $0.5 \mathrm{ml} \mathrm{S} 9 \mathrm{mix}$ or $0.1 \mathrm{ml}$ of a sterile $\beta$-glucuronidase solution $(1500 \mathrm{U} / \mathrm{ml})$, or a combination of both. ${ }^{4}$

\section{Workers}

Urine samples from the workers were gathered during 10 consecutive days, including two free weekends. During this period two urine samples were collected daily: one overnight and one between 10 am and $4 \mathrm{pm}$. The mutagenicity of the urine was determined according to van Doorn et al. ${ }^{5}$

\section{MONITORING OF CONTAMINATED SURFACES}

To detect contamination of work areas with mutagenic creosote we applied a method based on that described by Simmon and Peirce. ${ }^{6}$ Five millilitres of acetone or alcohol were put on a surface and the solvent was mopped up with a Kleenex tissue. The tissue was extracted twice with $25 \mathrm{ml}$ of acetone or alcohol. The acetone or alcohol was evaporated to dryness using a rotary evaporator. The total residue was dissolved in $5 \mathrm{ml}$ of dimethylsulphoxide (DMSO), and $0 \cdot 1 \mathrm{ml}$ of this solution was added per plate and assayed for mutagenicity with the $S$ typhimurium tester strain TA98 in the presence of S9 mix. Every determination was done in triplicate. After 48 hours' incubation at $37^{\circ} \mathrm{C}$ the number of revertant colonies on the plates was counted.

\section{Results}

MUTAGENICITY OF CREOSOTE

Table 1 shows the experimental results in which the mutagenicity of creosote was established. The mutagenicity was assayed using the $S$ typhimurium strains TA98 and TA100 in the presence of S9 mix and expressed as the number of revertant colonies per plate.

Table 1 Mutagenicity of creosote

\begin{tabular}{lll}
\hline $\begin{array}{l}\text { Creosote } \\
(\mu g / \text { plate })\end{array}$ & \multicolumn{2}{l}{ No of his ${ }^{+}$revertants per plate* } \\
\cline { 2 - 3 } & Strain \\
\cline { 2 - 3 } & TA98 & TA100 \\
\hline 0 & $16 \pm 4$ & $69 \pm 4$ \\
2 & $17 \pm 1$ & $87 \pm 9$ \\
5 & $21 \pm 2$ & $99 \pm 2$ \\
20 & $134 \pm 9$ & $284 \pm 12$ \\
50 & $336 \pm 7$ & $598 \pm 9$ \\
\hline
\end{tabular}

${ }^{*}$ Mean values \pm SEM of determinations in triplicate.

DETECTION OF MUTAGENIC SUBSTANCES IN THE WORK ENVIRONMENT

The work environment was examined for the presence of mutagenic substances. Spot samples were taken at several places from contaminated surfaces and tested for mutagenicity; the results are shown in table 2. Spots Nos 1, 2, 3, and 4 were on metal

Table 2 Contamination with mutagenic substances of some areas of the work environment ${ }^{*}$

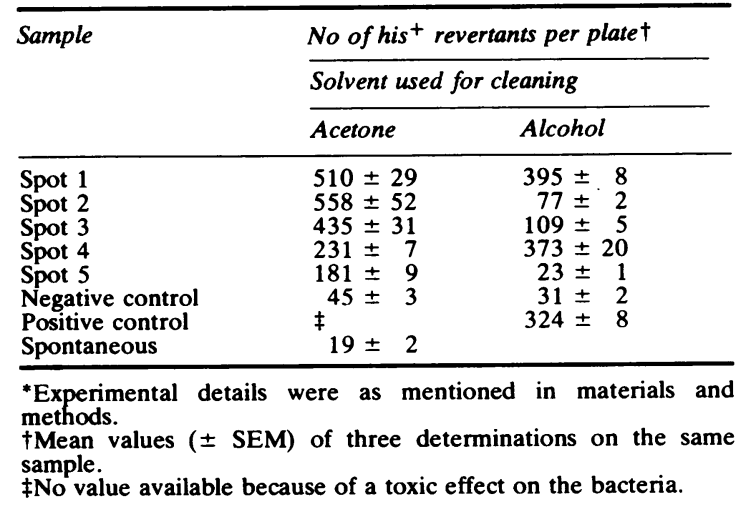


Table 3 Mutagenicity towards the Salmonella typhimurium strains TA98 and TA100 of urine from a creosote treated rat after the addition of different enzyme preparations

\begin{tabular}{|c|c|c|c|c|}
\hline \multirow[t]{4}{*}{ Addition $\ddagger$} & \multicolumn{4}{|c|}{ No of his ${ }^{+}$revertants/plate ${ }^{*}$} \\
\hline & \multicolumn{4}{|l|}{ Treatment } \\
\hline & \multicolumn{2}{|l|}{ Creosote $\dagger$} & \multicolumn{2}{|l|}{ Control } \\
\hline & $T A 98$ & $T A 100$ & TA98 & $T A 100$ \\
\hline $\begin{array}{l}\text { None } \\
\text { S9 mix } \\
\text { S9 mix + }\end{array}$ & $\begin{array}{l}43 \pm 2 \\
44 \pm 5\end{array}$ & $\begin{array}{l}188 \pm 9 \\
202 \pm 8\end{array}$ & $\begin{array}{l}37 \pm 1 \\
39 \pm 4\end{array}$ & $\begin{array}{l}175 \pm 8 \\
151 \pm 3\end{array}$ \\
\hline $\begin{array}{c}\beta \text {-glucuronidase } \\
\beta \text {-glucuronidase }\end{array}$ & $\begin{array}{r}123 \pm 8 \\
76 \pm 11\end{array}$ & $\begin{array}{l}341 \pm 10 \\
275 \pm 18\end{array}$ & $\begin{array}{l}43 \pm 3 \\
47 \pm 2\end{array}$ & $\begin{array}{l}175 \pm 12 \\
166 \pm 2\end{array}$ \\
\hline
\end{tabular}

*Mean values $( \pm$ SEM) of three measurements of the same urine. † Rats were injected intraperitoneally with a dose of $250 \mathrm{mg} / \mathrm{kg}$.

‡For experimental details see materials and methods.

One hundred and fifty units of $\beta$-glucuronidase were used.

surfaces. Spots 1 and 2 were on a grip of the door of the cylinder and on a handle very close to this door, respectively. Spot 3 was on the banisters about $3 \mathrm{~m}$ away from the cylinder. Spot 4 was on a lorry used to transport the wood in and out of the cylinder. Spot 5 was on wood that was not treated with creosote and which was piled up about $15 \mathrm{~m}$ away from the cylinder. A negative control was made from the surface of a clean table in our laboratory. A spot on the surface of creosoted wood served as a positive control. These results show that the work environment is contaminated with mutagenic substances. Extraction with acetone gave higher mutagenic values than extraction with alcohol.

ANIMAL EXPERIMENTS

Administration of creosote to rats $(250 \mathrm{mg} / \mathrm{kg}$ bodyweight, intraperitoneally) resulted in the appearance of mutagens in the urine detectable with the strains TA98 and TA100 (table 3). The highest mutagenicity values were detected after the addition of $\mathrm{S} 9 \mathrm{mix}$ in the presence of $\beta$-glucuronidase to the urine.

\section{ABSENCE OF MUTAGENICITY IN URINE OF CREOSOTE WORKERS}

We were interested whether the workers engaged in the preservative treatment of wood with creosote had mutagenic urine. We collected urine samples on 10 consecutive days but although using $S$ typhimurium TA98 in the presence of S9 mix and $\beta$-glucuronidase, we failed to detect an increase in urinary mutagenicity that could be related to their work.

\section{Discussion}

These results clearly show the presence of mutagenic substances in the work environment of a wood preserving industry, most likely due to the presence of creosote. The method used for monitoring the work environment for the presence of mutagens is easy to carry out and is based on the method of Simmon and Peirce ${ }^{6}$ who introduced it to detect the spillage of carcinogens and mutagens in laboratories. The present results suggest that the application in the work environment of this wipe test could give a first indication of occupational exposure to mutagenic and carcinogenic substances. This might be important, particularly in those cases where exposure can occur through skin contact rather than through inhalation.

Despite the substantial contamination of the work environment with mutagenic substances, no increase in mutagenicity in the workers' urine was detected in relation to their work. On the other hand, mutagens appeared in the urine of rats after intraperitoneal administration of creosote. Most probably the absence of mutagens in the urine of creosote workers can be attributed to (1) a relative low level of exposure-for instance, owing to the wearing of protective gloves, (2) the wrong choice of the time of taking urine samples, and (3) the insensitivity of the urinary mutagenicity assay. Presumably more selective methods of biological monitoring might give more information about internal exposure.

Financial support was obtained from the General Directorate of Labour, Dutch Ministry of Social Affairs.

After completion of this paper we characterised two important mutagenic components of creosote: benzo(a)pyrene and benz(a)anthracene. Concentrations of these components were found to be $0 \cdot 18 \%$ and $1 \cdot 1 \%$, respectively. ${ }^{\text {? }}$

\section{References}

' Bos RP, Hulshof CTJ, Theuws JLG, Henderson PT. Mutagenicity of creosote in the Salmonella/microsome assay. Mutation Res 1983;119:21-5.

2 Sax NL. Cancer causing chemicals. New York; Van Nostrand/ Reinhold, 1981:345.

${ }^{3}$ Ames BN, McCann J, Yamasaki E. Methods for detecting carcinogens and mutagens with the Salmonella/mammalian microsome mutagenicity test. Mutation Res 1975;31:347-64.

4 Bos RP, Brouns RME, van Doorn R, Theuws JLG, Henderson PT. The appearance of mutagens in urine of rats after the administration of benzidine and some other aromatic amines. Toxicology 1980;16:113-22.

${ }^{5}$ van Doorn R, Bos RP, Leydekkers Ch-M, Wagenaars-Zegers MAP, Theuws JLG, Henderson PT. Thioether concentration and mutagenicity of urine from cigarette smokers. Int Arch Occup Environ Health 1979;43:159-66.

- Simmon VF, Peirce MV. Design, implementation and monitoring of laboratories for handling chemical carcinogens and mutagens. In: Walters DB, ed. Safe handling of chemical carcinogens, mutagens, teratogens and highly toxic substances. Michigan; Ann Arbor, 1980:153-66.

' Bos RP, Theuws JLG, Leijdekkers CM, Henderson PT. The presence of the mutagenic polycyclic aromatic hydrocarbons benzo(a)pyrene and benz(a)anthracene in creosote P1. Mutation Research (in press). 